\title{
Usefulness of manometry to select patients with anal fissure for controlled anal dilatation
}

\author{
C. Santander, J. P. Gisbert, R. Moreno-Otero, A. G. McNicholl and J. Maté \\ Department of Gastroenterology and Coloproctology Unit. La Princesa University Hospital. Universidad Autónoma de \\ Madrid. Centro de Investigación Biomédica en Red de Enfermedades Hepáticas y Digestivas (CIBEREHD). Madrid, \\ Spain
}

\begin{abstract}
Aim: To evaluate the use of anorectal manometry to select patients for controlled anal dilatation.

Methodology: A prospective study was performed using anorectal manometry on all patients with chronic anal fissure who did not have a good response to conservative treatment. Those with increased anal resting pressure were treated with controlled anal dilatation using a two valved anuscope. A second anorectal manometry was indicated after controlled anal dilatation.

Results: 19 patients without anorectal pathology (Healthy Control Group) and 57 patients with chronic anal fissure were included in this study. Controlled anal dilatation was performed on 27 patients, maximum resting pressure $122 \pm 19 \mathrm{mmHg}$. In the controlled anal dilatation group the healing rate was $92.5 \%$, mean maximum resting pressure post-controlled anal dilatation was 91 $\pm 30 \mathrm{mmHg}$. We found one case of transitory anal incontinence (3.7\%). None of the patients had anal incontinence at 18 months of the follow-up. In the remaining 30 patients non selected for controlled anal dilatation (chronic anal fissure control group), a proportion of $53.3 \%$ recurrences were registered after conservative treatment.

Conclusions: Anal healing of chronic anal fissure and a significant decrease in maximum resting pressure recorded by manometry confirms the success of this procedure. The manometric evaluation of the maximum resting pressure is useful in the selection of chronic anal fissure patients for controlled anal dilatation. The efficacy of dilatation to treat chronic anal fissure in patients with raised anal sphincter pressure was high and complications were rare.
\end{abstract}

Key words: Manometry. Anus. Anal fissure. Anal sphincter. Spasm. Dilatation. Fecal incontinence.

Received: $12-02-10$.

Accepted: 30-04-10.

Correspondence: Cecilio Santander Vaquero. Servicio de Aparato Digestivo. Planta $3^{\text {a }}$. Hospital Universitario de La Princesa. C/ Diego de León, 62. 28006 Madrid, Spain.E-mail: ceciliosantander@hotmail.com
Santander C, Gisbert JP, Moreno-Otero R, McNicholl AG, Maté J. Usefulness of manometry to select patients with anal fissure for controlled anal dilatation. Rev Esp Enferm Dig 2010; 102: 691-697.

\section{INTRODUCTION}

Anal fissure is a common disorder, but its pathogenesis and aetiology are still not completely understood (1); however, studies using anorectal manometry have confirmed that resting anal pressure is elevated in these patient s (2). While the treatment of acute fissure is conservative (fibre supplementation, adequate fluid intake, sitz baths and analgesics), surgery is indicated for chronic anal fissure (3). Therapy is directed to reduce internal anal sphincter spasms, relieve of pain and improve the possible secondary ischemia of the anoderm (improving perfusion), thus facilitating the anal healing of the chronic fissure without recurrences (4). Lateral internal sphincterotomy, which is the treatment of choice $(5,6)$, may permanently lower anal resting pressure and allow healing in more than 95 percent of cases $(7,8)$, although it may be followed by soiling in a significant number of patients (9).

Among more conservative procedures, chemical sphincterotomy with glyceryl trinitrate ointment is directed at decreasing resting anal pressure. Early enthusiastic trials (healing rates of 70 to $80 \%$ ) have been tempered by more recent studies showing lower (25 to 50\%) healing rates (10-13); moreover, it may produce a recurrence rate of up to $50 \%$ and side effects, particularly headache (14). Locally injected botulin toxin has been used as an alternative approach to sphincter relaxation; there is concern, however, regarding the cost, toxicity and long-term atrophy of the external anal sphincter (15). 
Non controlled or non standardized manual anal dilatation (Lord's original procedure) has been abandoned because it is likely to damage anal sphincters, causing faecal incontinence; thus, sphincter defects were detected by endoanal ultrasonography in $13(65 \%)$ of 20 patients who underwent dilatation (16). By contrast, the standard technique to perform the procedure by fixing some parameters, such as the maximum diameter of dilatation anal duration, is widely accepted. Anal dilatation was standardized with Park's retractor (48 $\mathrm{mm}$ diameter), with pneumatic endoanal $40 \mathrm{~mm}$ balloon or with a two valved anuscope (45 $\mathrm{mm}$ diameter), the so called controlled anal dilation (1721). Controlled anal dilatation obtains high healing rates, adequate reduction in mean resting anal pressure and low rates of recurrence or incontinence and similar to those found in surgery (17-22). Because of the availability of such technique, controlled anal dilatation has become a reliable, easily reproducible, easier to learn and perform, and non-operator-dependent procedure (19).

The aim of this prospective study was to evaluate the use of anorectal manometry to select patients with chronic anal fissure for controlled anal dilatation using a two valved anuscope. Secondary objectives were the clinical and functional follow-up of chronic anal fissure patients and the relation between maximum resting pressure reduction and complete healing.

\section{METHODS}

\section{Patients}

This prospective study was performed applying anorectal manometry to all patients with chronic anal fissure who did not respond to non-invasive treatment. Anal spasm patients (anal resting pressure higher than mean \pm $\mathrm{SD}$ of control group, $\mathrm{mmHg}$ ) were treated with controlled anal dilatation under local anaesthesia using a two valved anuscope (Richard Woolf 8849 00), maximum dilatation $45 \mathrm{~mm}$. A second anorectal manometry was indicated one month after controlled anal dilatation.

Nineteen patients without anorectal symptoms, paired (1:3) for age, were selected as healthy control group, and underwent anuscopy and anorectal manometry, in order to use the mean values of maximum resting pressure and maximum squeeze pressure as values of reference.

Anal fissures are longitudinal tears or ulcers in the distal anal canal, extending below the dentate line to the anal verge (anoderm, anal scamous epithelium). We defined chronic anal fissure as an ulcer with indurated edges, exposure of the horizontal fibres of the internal anal sphincter at the base, hypertrophied anal papillae or anal skin tag (sentinel tag), and a duration of symptoms for at least eight weeks.

Fifty seven consecutive patients, observed at the Colorectal Unit, La Princesa University Hospital, Madrid, over 1 year with chronic anal fissure who had a failure to non-invasive treatment (high-residue diet, laxatives, analgesics, and warm hip-bath, for at least 8 weeks), were prospectively enrolled in this study.

The exclusion criteria were: associated anal pathologies (incontinence, stenosis, abscess, fistula, or hemorrhoids), systemic conditions (coagulopathy, inflammatory bowel disease, acquired immunodeficiency syndrome, immunosuppression, pregnancy or vaginal delivery 8 months ago), or past history of undergone surgery for anal lesions or radiotherapy in the pelvic or perineal area.

The protocol was performed according to the principles of the declaration of Helsinki. The study received ethical approval by the Ethical Committee of our Hospital and each patient provided written informed consent before study participation.

Information regarding age, sex, symptoms, bowel habits, examination findings, and anal manometric values was collected at the time of inclusion. Early and late complications, fissure healing, and recurrence were collected at inclusion and during follow-up. A second anorectal manometry was indicated one month after controlled anal dilatation and the follow-up consisted of telephone interviews 6 and 18 months after the end of treatment.

Out of 57 patients with chronic anal fissure, 27 were treated with controlled anal dilatation; the remaining 30 patients no selected for controlled anal dilatation were considered as chronic anal fissure control group. All 30 underwent anorectal manometry at the time of admission, and a second anorectal manometry was performed after 18 months of follow-up.

\section{Manometry}

Anorectal manometry was indicated for all patients at inclusion and 4 weeks after controlled anal dilatation. Anorectal manometry was performed using a computerized perfusion system with a 4 lumen catheter $(4.5 \mathrm{~mm}$ diameter) having radially arranged ports in cross-section. Perfusion was performed with distilled water through a low-compliance pump at a constant rate of $0.5 \mathrm{ml} / \mathrm{min}$ with $1.2 \mathrm{~kg} / \mathrm{cm}^{2}$ flow, and a continuous and stationary pull-through procedure (The PolygrafTM ID multiparametric recorder with POLYGRAM NET ${ }^{\circledast}$ analysis software, Medtronic, Sweden). The following parameters were considered: length of the sphincter in centimetres, maximum resting pressure and maximum squeeze pressure in $\mathrm{mmHg}$, and slow and ultraslow activity.

Anal spasm was defined by an anal resting pressure higher than mean plus standard deviation (SD) of control group, a value higher than $89 \mathrm{mmHg}(19,23,24)$.

In patients with maximum resting pressure lower than $89 \mathrm{mmHg}$, controlled anal dilatation was not indicated, and continuation of conservative treatment was proposed (fibre supplementation, adequate fluid intake, hip-baths, analgesics and glyceryl trinitrate ointment). 
Anal incontinence, when present, was assessed using Wexner (25) scoring and grading system (range 0 to 20). Patients also underwent both anatomic and functional evaluation of the anal sphincter with an ecoendoscope Olympus EUSEXERA EU-M60 (26-29). Ecoendoscope with a $360^{\circ}$ mechanical rotating transducer and work frequency ranging between 7.5 an $12 \mathrm{MHz}$ for morphologic evaluation of the anal sphincters and anorectal manometry was used.

\section{Controlled anal dilatation procedure}

A $140 \mathrm{ml}$ enema was administered the afternoon/evening of the day before controlled anal dilatation. Patients were treated under local anaesthesia. 40-80 mg of articaine were administered through a multineedle device in the commissure affected by the chronic anal fissure. The patient is placed in the genupectoral position. A bivalves anuscope (Richard Woolf 8849 00) (Fig. 1) was introduced after adequate lubrication in the anal canal and. Afterwards blades were slowly opened laterally until the blades become parallel in order to reach a maximum transverse diameter of $45 \mathrm{~mm}$. Dilation was maintained in situ for 4 minutes, and then blades were slowly closed and the anuscope removed. These parameters (diameter and duration) were predetermined.

Hypertrophied anal papillae, if present, were removed with a polipectomy handle. The patients were discharged on the same day with instructions regarding high-residue diet, laxatives, analgesics (Metamizol), and warm water hip-bath.

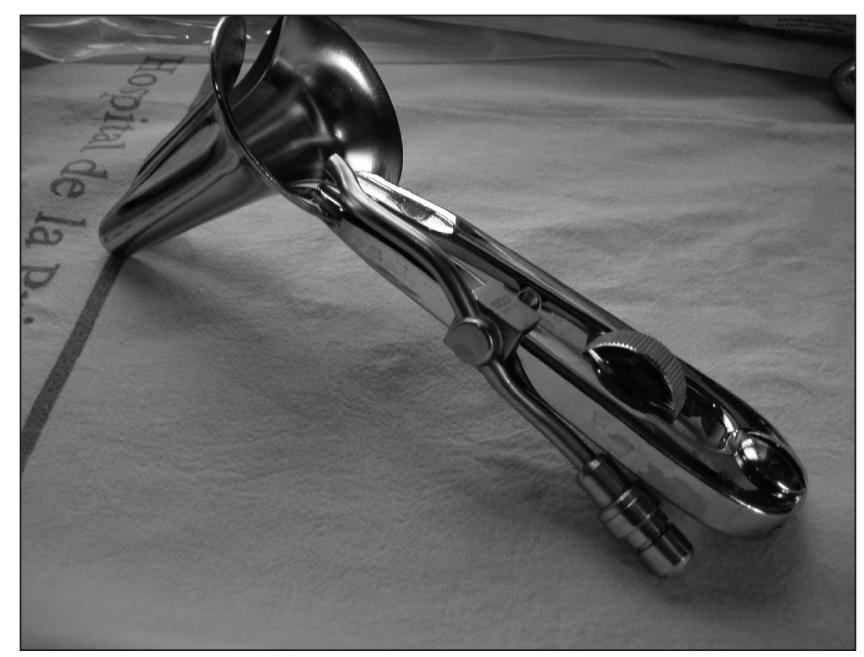

Fig. 1. Bivalves anuscope (Richard Woolf 8849 00) used for controlled anal dilatation.

\section{Follow-up}

For each patient a fibre-rich diet with a bulking agent supplement (Psyllium plantago) was prescribed. Postreatment anal pain was treated with analgesics (metamizol).
All patients were reassessed clinically one month after controlled anal dilatation. The patients whose symptoms were resolved and whose anoderma reepithelized were considered cured. During the visit, patients filled a Wexner incontinence questionnaire (25), a clinical evaluation was performed, and the possible onset of side effects was recorded; a further anorectal manometry was performed only on those patients for whom the symptoms had not been reduced and/or who had suffered a recurrence of chronic anal fissure.

When chronic anal fissure healing was not reached after 4-5 weeks, a new clinical review was planned. If there was high persistence, a second controlled anal dilatation was performed. If a second therapeutic failure happens we recommended a lateral internal sphincterotomy. During the eighteen months follow-up period, patients were instructed to report any onset of disorders.

The follow-up consisted of a telephone interview 6 and 18 months after the end of treatment to ask all the patients about the recurrence of anal symptoms and faecal involuntary leaks. We recommended attending the Hospital to perform an anal exploration when they referred suggestive symptoms of anal fissure. Likewise, if patients complained about the possibility faecal involuntary leaks, they were asked to fill in the questionnaire of health in anal continence (Wexner incontinence questionnaire), and in the event of suspicion, an anal ultrasound endoscopy (USE) was performed by means of an ecoendoscope Olympus EUSEXERA EU-M60.

In the chronic anal fissure control group (30 patients) a second anorectal manometry was indicated 18 months after the follow-up.

\section{Statistical analysis}

The results were expressed as mean \pm standard deviations. The $95 \%$ confidence interval was calculated for categorical variables.

The paired sample t-test was performed to compare the variation in maximum resting pressure and maximum squeeze pressure pre-treatment and post-treatment. The difference was considered statistically significant at $p<$ 0.05 .

\section{RESULTS}

\section{Patients}

A total of 19 people without anorectal pathology (healthy control group) and 57 patients with chronic anal fissure were included in this study. Of this last group, 33 were male (58\%) and 24 female (42\%), with a mean age of $47 \pm 13$ years old. The mean duration of symptoms was $18 \pm 20$ weeks. 


\section{Anuscopy}

The chronic anal fissure was located at the posterior commissure in 45 patients (79\%). All 57 patients (100\%) complained of pain during defecation and 51 of them (89\%) bleeding. The examination detected the presence of sentinel tag in 44 patients (77\%) and a hypertrophic anal papilla in 45 (79\%). In addition 34 patients $(60 \%)$ complained of constipation.

\section{Anorectal manometry}

The average length of the anal canal was $3.4 \pm 0.3 \mathrm{~cm}$. We found that 38 patients $(67 \%)$ presented slow waves and 28 patients $(49 \%)$ ultraslow waves.

Maximum resting pressure was increased in 35 patients $(61 \%)$ and was normal in $22(39 \%)$. In 22 patients we found a maximum resting pressure inside reference rang (maximum resting pressure lower than $89 \mathrm{mmHg}$ ) therefore, controlled anal dilatation was not indicated.

\section{Controlled anal dilatation}

Thirty five patients had increased maximum resting pressure. Five patients rejected the treatment, two patients were excluded due to oral anticoagulation treatment and one patient suffered an anxiety crisis before initiating the anaesthetic procedure. Thus, controlled anal dilatation was performed in 27 patients $(77 \%)$. All of them presented hypertonic internal anal sphincter, mean maximum resting pressure pressure $122 \pm 19 \mathrm{mmHg}$ (Table I). Hypertrophied anal papillae were removed in 12 patients (44\%), without complications and showing good tolerance.
The healing rate was $93 \%$ (95\% CI: 76-99\%) and mean maximum resting pressure post-controlled anal dilatation was $91 \pm 30 \mathrm{mmHg}(\mathrm{p}<0.002)$; the reduction of the basal pressure was $25 \%$ (Figs. 2 and 3). There was no statistical difference in the length of the sphincter area pre-controlled anal dilatation and post-controlled anal dilatation: $3.4 \pm 0.3 \mathrm{~cm}$ and $3.4 \pm 0.4 \mathrm{~cm}$, respectively.

In two patients $(7.4 \%$; $95 \% \mathrm{CI}$ : $0.9-24 \%)$ the absence of chronic anal fissure healing was demonstrated by anuscopy 8 weeks after controlled anal dilatation procedure; these patients were considered treatment failures by fissure persistence and in both cases the maximum resting pressure remained high. Due to the persistence of a raised maximum resting pressure in both cases (145 and $186 \mathrm{mmHg}$ ), a second controlled anal dilatation was indicated. The second controlled anal dilatation also failed in both cases and the maximum resting pressure was persistently high (verified by means of third anorectal manometry; 130 and $158 \mathrm{mmHg}$ ); both patients were submitted to the Surgery Department to program a internal lateral sphincterotomy, reaching finally the healing of the fissures.

\section{Complications and follow-up}

Minor haemorrhage was observed in all patients and no treatment was needed. No anal infection was observed.

A transitory anal incontinence for flatus occurred in a woman $(3.7 \%)$ and spontaneously resolved within 5 days. Anal ultrasounds were normal (without defects to the sphincters) and pre and post-treatment maximum resting pressure were 121 and $100 \mathrm{mmHg}$ respectively; pre and post-treatment maximum squeeze pressure were 151 and $109 \mathrm{mmHg}$ respectively. None of the patients

Table I. Anorectal Physiology results before and after treatment

\begin{tabular}{lcccccc}
\hline & $\begin{array}{c}\text { No. of } \\
\text { patients }\end{array}$ & \multicolumn{2}{c}{ Before treatment } & \multicolumn{2}{c}{ Four weeks after CAD } & $\begin{array}{c}\text { End of follow-up } \\
\text { (18 months) }\end{array}$ \\
\hline Healthy Control Group & 19 & $67 \pm 22$ & $174 \pm 65$ & - & MSP & - \\
\hline All patients CAF & 57 & $106 \pm 27$ & $201.6 \pm 61$ & - & - & MSP \\
\hline CAF and MRP normal & 22 & $81.5 \pm 22$ & $174 \pm 52$ & - & - \\
\hline CAF and MRP increased & 35 & $118.4 \pm 20$ & $212 \pm 46$ & & $174.4 \pm 38$ \\
\hline CAF group & 27 & $122 \pm 19 *$ & $219.3 \pm 59$ & $91 \pm 30 *$ & 145 & 274 \\
\hline CAD failure & 2 & 136 & 268 & 186 & 253 \\
\hline CAF recurrences & 4 & $103 \pm 19$ & $202 \pm 36$ & $121 \pm 20$ & $214 \pm 21$ \\
\hline CAF Control Group & 30 & $91 \pm 21$ & $188 \pm 64$ & - & - \\
\hline
\end{tabular}

SD: Standard deviation. CAF: Chronic anal fissure. CAD: Controlled anal dilation. MRP: maximum resting pressure (mmHg). MSP: maximum squeeze pressure (mmHg). $* p<0.002$. 


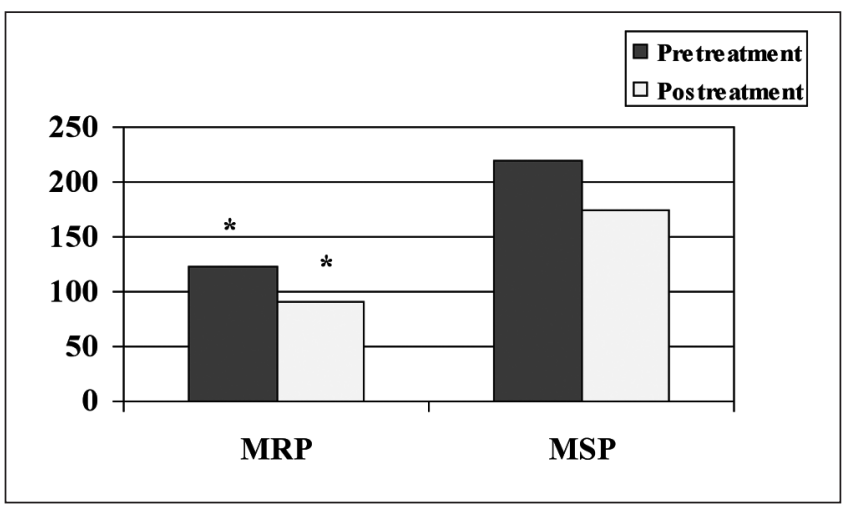

Fig. 2. Maximum resting pressure (MRP, $\mathrm{mmHg}$ ) and maximum squeeze pressure (MSP, $\mathrm{mmHg}$ ) pre-controlled anal dilation and 1 month post- controlled anal dilatation in patients with chronic anal fissure and internal anal sphincter spasm.

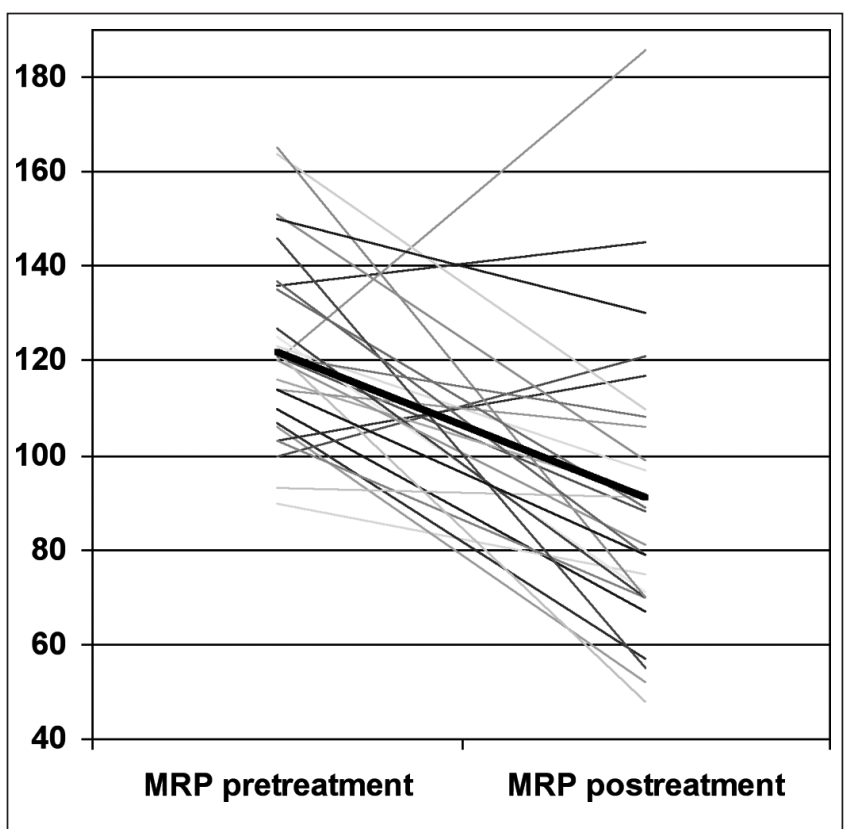

Fig. 3. Reduction of maximum resting pressure (MRP, $\mathrm{mmHg}$ ). Values pre-controlled anal dilation and 1 month post- controlled anal dilatation in patients with chronic anal fissure and internal anal sphincter spasm. Include mean in bold line.

had anal incontinence 18 months after controlled anal dilatation.

Fissure recurrence was observed in four patients (14.8\%; 95\% CI: 4-34\%) in the chronic anal fissure Group: a second dilatation was performed in 3 of them and lateral internal sphincterotomy in the other one. The manometric test showed that the pressure values 4 weeks post- controlled anal dilatation were greater than the general controlled anal dilatation group $(121 \pm 20 \mathrm{mmHg} v s$ $91 \pm 30 \mathrm{mmHg}, \mathrm{p}<0.002)$. Patients were symptom-free 18 months after the second procedure.

In the 30 patients defined as the chronic anal fissure control group (no controlled anal dilatation), a proportion of $53.3 \%$ recurrences were registered. A second anorectal manometry was performed in all 18 months after the follow-up. Basal mean pressure was $91 \pm 21 \mathrm{mmHg}$ and 84 $\pm 26 \mathrm{mmHg} 18$ months later (Table I). Basal and 18 months later maximum squeeze pressure values were 188 $\pm 64 \mathrm{mmHg}$ and $186 \pm 61 \mathrm{mmHg}$ respectively, and no statistical differences were observed.

No patient was lost during follow-up period. Noticeable, none of the patients had anal incontinence at the end of the follow-up.

\section{DISCUSSION}

No single treatment for chronic anal fissure exists for all patients and is a topic still open to debate (30). According to the pathophysiologic mechanisms, such as internal anal sphincter hypertonia and inadequate blood flow to the anoderm, several treatment options have been developed to restore normal sphincter tone and allow fissure healing. These options include both pharmacological and invasive therapies. The main advantages of invasive treatment are rapid pain relief, high success rate, low relapses rate, technical simplicity and minimum morbidity. The internal lateral sphincterotomy is considered at present the gold standard therapy $(5,6,31)$ in chronic anal fissure achieving more than 95 percent of healing rates $(7,8)$; additionally, this procedure permanently reduces anal resting pressure and allows healing, but it may be followed by faecal incontinence in a variable number of patients, between 1.3 and $66 \%(9,32,33)$.

Anal dilatation has been widely criticized for causing poorly controlled or diffuse sphincter damage, and is not a completely accepted procedure. Anal dilatation literature must be read with caution. The exact technique varies between, and sometimes within, series. Important variables, such as the extent and duration of sphincter stretch or the type of anesthesia, are often neither specified nor standardized. Many reports of anal dilatation are relatively old and details regarding continence assessment are frequently lacking, suggesting that reported incontinence rates may actually represent minimal figures.

In 1992 Sohn et al. (17) demonstrated that anal dilatation, when performed in a precise and controlled manner using a $40 \mathrm{~mm}$ rectosigmoid balloon inflated to $20 \mathrm{psi}$ for 5 minutes, successfully cured 93.5 percent of anal fissures, with fewer complications than anal sphincterotomy (Table II). In 1997 he reported on a series of 319 patients with chronic anal fissure treated by balloon dilatation, and $88 \%$ of them healed within 3 months (34). There were two cases $(0.6 \%)$ of temporary incontinence to flatus and one case of permanent incontinence to flatus; no cases of temporary or permanent incontinence to liquid or solid stool existed and there were no problems with soiling (30).

Renzi et al. (24) published a study comparing controlled dilatation (using a $40 \mathrm{~mm}$ diameter pneumatic bal- 
Table II. Results of controlled anal dilation for chronic anal fissure

\begin{tabular}{|c|c|c|c|c|c|c|c|c|}
\hline Study & Year & $\begin{array}{l}\text { No. of } \\
\text { patients }\end{array}$ & $\begin{array}{l}\text { Follow-up } \\
\text { (months) }\end{array}$ & $\begin{array}{l}\text { Method: diameter } \\
(\mathrm{mm})\end{array}$ & $\begin{array}{l}\text { Healing } \\
\%\end{array}$ & $\begin{array}{c}\text { Recurrence } \\
\%\end{array}$ & $\begin{array}{c}\text { Minor soiling } \\
\%\end{array}$ & $\begin{array}{c}\text { Complications } \\
\%\end{array}$ \\
\hline Sohn et al. (20) & 1992 & 105 & 3 & $\begin{array}{c}\text { Balloon (40) } \\
\text { or Park's retractor (48) }\end{array}$ & 93.5 & 2 & 2 & 1.5 \\
\hline Sohn et al. (37) & 1997 & 292 & - & Balloon (40) & 88 & 12 & 1 & 0.7 \\
\hline Renzi et al. (22) & 2004 & 33 & 25 & Balloon (40) & 94 & 3 & $\begin{array}{l}6 \text { (6 months) } \\
0 \text { (12 months) }\end{array}$ & 0 \\
\hline Renzi et al. (31) & 2008 & 24 & 24 & Balloon 40 & 83.3 & 0 & $\begin{array}{l}16.6 \text { ( } 6 \text { weeks }) \\
0 \text { (24 months) }\end{array}$ & 0 \\
\hline
\end{tabular}

loon) with lateral internal sphincterotomy. Fissure-healing rates at six weeks after the intervention were $83.3 \%$ in the dilatation group and $92 \%$ in the sphincterotomy group, but the rate of postoperative anal incontinence was significantly lower in the dilatation group. Minor soiling was observed in 4 of the 24 patients (16\%) who underwent dilatation, and in all four the disturbances disappeared after 12 months. In the sphincterotomy group 7 of 25 patients $(28 \%)$ reported deterioration in continence at the first postoperative week, and 4 of them (16\%) had continence disturbances at two years after the operation.

Our results are comparable to those of the series of Boschetto et al. (18) on chronic anal fissure patients. Recovery rate with hydropneumatic anal dilation using Microvasive Rigiflex instrument $(40 \mathrm{~mm})$ was $79.8 \%$ after 10 days and $94.5 \%$ after 30 days. An immediate (within the first 24 hours) relief was observed in the level of pain. Healing rate was $94.5 \%$ applying this technique and no significant complications or recurrences were reported within 2 years follow-up. Previous studies without anorectal manometry showed soiling in $14.6 \%$ of patients with anal dilatation and in $9.5 \%$ with sphincterotomy vs. $0 \%$ in our 27 patients treated with controlled anal dilatation (2022). We have been able to reduce the rate of complications probably because of evaluation by anal manometry before the endoscopic dilation procedure (35).

A normal maximum resting pressure post-controlled anal dilatation associates with complete cicatrisation during the follow-up, but when the maximum resting pressure post-controlled anal dilatation remains high a therapeutic failure was recorded. Anal healing of chronic anal fissure and a statistically significant decrease in maximum resting pressure at 1 month post-controlled anal dilatation recorded by manometry confirms the success of this technique. The manometric evaluation of maximum resting pressure before the performance of invasive techniques in chronic anal fissure improves success rates and avoids inadequate procedures, without an increased risk of anal incontinence. However, a follow-up period of 18 months, as in our study, may be too short evaluating anal incontinence because these effects may take years to manifest clinically and other factors, such as menopause or subsequent childbirth, may induce longer term incontinence.
Controlled anal dilatation was well tolerated in our patients using bivalves anuscope. Controlled anal dilatation was carried out in ambulatory regimen, all patients returned to their homes on the treatment day, and incorporation to daily activities was allowed the day following procedure. The complete procedure, considered since the patient enters the cabin to change clothes to its exit with the report of the procedure, has an average duration of 20 \pm 4.2 minutes (36).

Internal anal sphincter hypertonia is not present in all chronic anal fissure patients $(4,37,38)$ and in this study, internal anal sphincter hypertonia was present in $61.4 \%$ (35/57 patients). A normal or diminished internal anal sphincter pressure in presence of chronic anal fissure must raise the suspicion of an atypical anal fissure (39) or the existence of an underlying condition such as Crohn's disease, ulcerative colitis, cancer, leukaemia, syphilis, tuberculosis or HIV. In this specific group of patients invasive treatment of chronic anal fissure is not appropriate.

In conclusion, our results suggest that manometric evaluation of the maximum resting pressure is useful in the selection of the patients for controlled anal dilatation. The efficacy of dilatation to treat chronic anal fissure in patients with raised anal sphincter pressure was high and complications were rare. Determining mean anal resting pressure may be of value in order to avoid postreatment continence problems, especially in older patients, women with vaginal deliveries, those with previous sphincter injuries or perineal lacerations, or patients with inflammatory bowel disease, and those with chronic diarrhoea.

\section{ACKNOWLEDGEMENT}

CIBEREHD is supported by the Instituto de Salud Carlos III, Madrid, Spain.

\section{REFERENCES}

1. Hananel N, Gordon PH. Re-examination of clinical manifestations and response to therapy of fissure-in-ano. Dis Colon Rectum 1997; 40(2): 229-33.

2. Farouk R, Duthie GS, MacGregor AB, Bartolo DC. Sustained internal sphincter hypertonia in patients with chronic anal fissure. Dis 
Colon Rectum 1994; 37: 424-9.

3. Rosen L, Abel ME, Gordon PH, Denstman FJ, Fleshman JW, Hicks TC, et al. Practice parameters for the management of anal fissure. The Standards Task Force American Society of Colon and Rectal Surgeons. Dis Colon Rectum 1992; 35(2): 206-8.

4. Lund JN, Scholefield JH. Aetiology and treatment of anal fissure. $\mathrm{Br}$ J Surg 1996; 83(10): 1335-44.

5. Ravikumar TS, Sridhar S, Rao RN. Subcutaneous lateral internal sphincterotomy for chronic fissure-in-ano. Dis Colon Rectum 1982; 25(8): 798-801.

6. Viso Pons L, Beatobe Muntada J. Internal lateral sphincterectomy. Results). Rev Esp Enferm Apar Dig 1989; 75(6 Pt 1): 589-92.

7. Nelson RL. A review of operative procedures for anal fissure. J Gastrointest Surg 2002; 6(3): 284-9.

8. Madoff RD, Fleshman JW. AGA technical review on the diagnosis and care of patients with anal fissure. Gastroenterology 2003; 124(1): 235-45.

9. Khubchandani IT, Reed JF. Sequelae of internal sphincterotomy for chronic fissure in ano. Br J Surg 1989; 76(5): 431-4.

10. Lund JN, Scholefield JH. A randomised, prospective, double-blind, placebo-controlled trial of glyceryl trinitrate ointment in treatment of anal fissure. Lancet 1997; 349(9044): 11-4.

11. Lund JN, Scholefield JH. Follow-up of patients with chronic anal fissure treated with topical glyceryl trinitrate. Lancet 1998; 352(9141): 1681 .

12. Knight JS, Birks M, Farouk R. Topical diltiazem ointment in the treatment of chronic anal fissure. Br J Surg 2001; 88(4): 553-6.

13. Altomare DF, Rinaldi M, Milito G, Arcana F, Spinelli F, Nardelli N, et al. Glyceryl trinitrate for chronic anal fissure--healing or headache? Results of a multicenter, randomized, placebo-controled, double-blind trial. Dis Colon Rectum 2000; 43(2): 174-9; discussion 9-81.

14. Carapeti EA, Kamm MA, McDonald PJ, Chadwick SJ, Melville D, Phillips RK. Randomised controlled trial shows that glyceryl trinitrate heals anal fissures, higher doses are not more effective, and there is a high recurrence rate. Gut 1999; 44(5): 727-30.

15. Jost WH. One hundred cases of anal fissure treated with botulin toxin: early and long-term results. Dis Colon Rectum 1997; 40(9): 102932.

16. Nielsen MB, Rasmussen OO, Pedersen JF, Christiansen J. Risk of sphincter damage and anal incontinence after anal dilatation for fissure-in-ano. An endosonographic study. Dis Colon Rectum 1993; 36(7): 677-80.

17. Sohn N, Eisenberg MM, Weinstein MA, Lugo RN, Ader J. Precise anorectal sphincter dilatation--its role in the therapy of anal fissures. Dis Colon Rectum 1992; 35(4): 322-7.

18. Boschetto S, Giovannone M, Tosoni M, Barberani F. Hydropneumatic anal dilation in conservative treatment of chronic anal fissure: clinical outcomes and randomized comparison with topical nitroglycerin. Tech Coloproctol 2004; 8(2): 89-92

19. Renzi A, Brusciano L, Pescatori M, Izzo D, Napolitano V, Rossetti $\mathrm{G}$, et al. Pneumatic balloon dilatation for chronic anal fissure: a prospective, clinical, endosonographic, and manometric study. Dis Colon Rectum 2005; 48(1): 121-6.

20. Fernández Bermejo M, M.P.E., Prieto Bermejo A, Mateos Rodríguez J, Fernández Salazar L, Maté Jiménez J. Dilatación endoscópica de la fisura anal. Rev Esp Enferm Dig 1999; 91(Supl. I): 172-229.
21. Perez-Miranda M, Robledo P, Alcalde M, Gomez-Cedenilla A, Mate Jimenez J. Endoscopic anal dilatation for fissure-in-ano: a new outpatient treatment modality. Rev Esp Enferm Dig 1996; 88(4): 265 72.

22. Perez-Miranda M, Jimenez JM. Treatment of chronic anal fissure. N Engl J Med 1998; 338(23): 1698-9.

23. Gupta PJ. Internal anal sphincterolysis for chronic anal fissure: a prospective, clinical, and manometric study. Am J Surg 2007; 194(1): 13-6.

24. Renzi A, Izzo D, Di Sarno G, Talento P, Torelli F, Izzo G, et al. Clinical, manometric, and ultrasonographic results of pneumatic balloon dilatation vs. lateral internal sphincterotomy for chronic anal fissure: a prospective, randomized, controlled trial. Dis Colon Rectum 2008; 51(1): 121-7.

25. Jorge JM, Wexner SD. Etiology and management of fecal incontinence. Dis Colon Rectum 1993; 36(1): 77-97.

26. M. Mínguez Pérez and A. Benages Martínez. The Bristol scale - a useful system to assess stool form?. Rev Esp Enferm Dig 2009; 101 (5): 305-11.

27. D. García-Olmo and I. Pascual Migueláñez. A sonograph in the proctology clinic - an aid to the "learned finger". Rev Esp Enferm Dig 2010; 102 (1): 1-6.

28. Pascual, I.; García-Olmo, D.; Martínez-Puente, C. and Pascual-Montero, J. A.. Ultrasound findings in spontaneous and postoperative anal pain. Rev Esp Enferm Dig 2008; 100(12): 764-7.

29. M. J. García-Montes, F. Argüielles-Arias, S. Jiménez-Contreras, S Sánchez-Gey, F. Pellicer-Bautista and J. M. Herrerías-Gutiérrez. Should anorectal ultrasonography be included as a diagnostic tool for chronic anal pain?. Rev Esp Enferm Dig 2010; 102(1): 7-11.

30. Steele SR, Madoff RD. Systematic review: the treatment of anal fissure. Aliment Pharmacol Ther 2006; 24(2): 247-57.

31. Jensen SL, Lund F, Nielsen OV, Tange G. Lateral subcutaneous sphincterotomy versus anal dilatation in the treatment of fissure in ano in outpatients: a prospective randomised study. Br Med J (Clin Res Ed) 1984; 289(6444): 528-30.

32. Nyam DC, Pemberton JH. Long-term results of lateral internal sphincterotomy for chronic anal fissure with particular reference to incidence of fecal incontinence. Dis Colon Rectum 1999; 42(10): 1306-10.

33. Pernikoff BJ, Eisenstat TE, Rubin RJ, Oliver GC, Salvati EP. Reappraisal of partial lateral internal sphincterotomy. Dis Colon Rectum 1994; 37(12): 1291-5

34. Sohn N, Weinstain M. Anal dilatation for anal fissure. Semin Colon Rectal Surgery 1997: 17-23.

35. Santander C, Moreno-Otero R, Mate J. Anorectal manometry and anal fissure treatment. Letters to the editors. Aliment Pharmacol Ther 2006; 24(11-12): 1651-2; author reply 2.

36. Cantero Perona J, Valbuena Gonzalez M, Briz Romero MR, Gonzalez Moreno L, Mate Jimenez J. Complexity index and analysis of digestive endoscopies at a university hospital. Gastroenterol Hepatol 2002; 25: 71-8

37. Nelson, R. Operative procedures for fissure in ano. Cochrane Database Syst Rev 2005 (2): p. CD002199.

38. Nothmann BJ, Schuster MM. Internal anal sphincter derangement with anal fissures. Gastroenterology 1974; 67(2): 216-20.

39. Viamonte M, Dailey TH, Gottesman L. Ulcerative disease of the anorectum in the HIV \pm patient. Dis Colon Rectum 1993; 36(9): 801-5. 